\title{
Acyl-CoA-binding protein family members in laticifers are possibly involved in lipid and latex metabolism of Hevea brasiliensis (the Para rubber tree)
}

Zhiyi Nie ${ }^{1+}$, Yihang Wang ${ }^{1,2+}$, Chuntai Wu' ${ }^{1}$, Yu Li ${ }^{1}$, Guijuan Kang ${ }^{1}$, Huaide Qin ${ }^{1}$ and Rizhong Zeng ${ }^{1 *}$

\begin{abstract}
Background: Acyl-CoA-binding proteins (ACBPs) are mainly involved in acyl-CoA ester binding and trafficking in eukaryotic cells, and their various functions have been characterized in model plants, such as Arabidopsis thaliana (A. thaliana), Oryza sativa (rice), and other plant species. In the present study, genome-wide mining and expression analysis of ACBP genes was performed on Hevea brasiliensis (the para rubber tree), the most important latex-producing crop in the world.

Results: Six members of the $H$. brasiliensis ACBP family genes, designated HbACBP1-HbACBP6, were identified from the $H$. brasiliensis genome. They can be categorized into four classes with different amino acid sequences and domain structures based on the categorization of their A. thaliana counterparts. Phylogenetic analysis shows that the HbACBPs were clustered with those of other closely related species, such as Manihot esculenta, Ricinus communis, and Jatropha carcas, but were further from those of $A$. thaliana, a distantly related species. Expression analysis demonstrated that the $\mathrm{HbACBP} 1$ and HbACBP2 genes are more prominently expressed in $\mathrm{H}$. brasiliensis latex, and their expression can be significantly enhanced by bark tapping (a mechanical wound) and jasmonic acid stimulation, whereas HbACBP3HbACBP6 had almost the same expression patterns with relatively high levels in mature leaves and male flowers, but a markedly low abundance in the latex. HbACBP1 and HbACBP2 may have crucial roles in lipid and latex metabolism in laticifers, so their subcellular location was further investigated and the results indicated that HbACBP1 is a cytosol protein, whereas HbACBP2 is an endoplasmic reticulum-associated ACBP.
\end{abstract}

Conclusions: In this study, the H. brasiliensis ACBP family genes were identified. Phylogenetic analyses of the HbABCPs indicate that there is a high conservation and evolutionary relationship between ACBPs in land plants. The HbACBPs are organ/tissue-specifically expressed and have different expression patterns in response to stimulation by bark tapping or ethrel/jasmonic acid. HbACBP1 and HbACBP2 are two important latex ACBPs that might be involved in the lipid and latex metabolism. The results may provide valuable information for further investigations into the biological functions of HbACBPs during latex metabolism and stress responses in $\mathrm{H}$. brasiliensis.

Keywords: Hevea brasiliensis, Acyl-CoA-binding protein (ACBP), Laticifer, Latex production, Rubber biosynthesis

\footnotetext{
* Correspondence: hnzrz@aliyun.com

${ }^{\dagger}$ Equal contributors

${ }^{1}$ Rubber Research Institute \& Key Laboratory of Biology and Genetic

Resources of Rubber Trees, Ministry of Agriculture of China, Chinese

Academy of Tropical Agricultural Sciences, Danzhou, Hainan 571737, China

Full list of author information is available at the end of the article
} 


\section{Background}

Acyl-CoA-binding proteins (ACBPs) have a conserved acyl-CoA-binding domain (ACBD) that binds to ligands of medium- and long-chain acyl-CoA esters with very high affinities [1-3]. ACBPs are mainly involved in intracellular transport and acyl-CoA pool formation during lipid metabolism $[4,5]$. The comprehensively characterized ACBP contains only about 90 amino acids (with an approximate molecular weight of $10 \mathrm{kDa}$ ), which is highly conserved and found in all four eukaryotic kingdoms and in some eubacterial species [6]. Plant ACBPs have been investigated in the model plants Arabidopsis thaliana (A. thaliana) and Oryza sativa (rice) $[7,8]$, and more ACBP genes have recently been characterized after genome sequencing other plant species e.g. Brassica napus [9], and the tung tree (Vernicia fordii) [10]. Phylogenetic analysis of ACBPs extracted from 30 plant genomes demonstrated that plant ACBPs can be grouped into four classes that have clear differences in their amino acids and structural domains. Classes I and III possess only one ACBD, class II contains one ACBD plus ankyrin repeats, and class IV contains one ACBD plus kelch motifs [11].

The A. thaliana ACBP family has six members (designated AtACBP1-AtACBP6) that have diverse functions in a number of plant developmental processes and responses to biotic or abiotic stresses [11-13]. AtACBP1 and AtACBP2, belong to class II ACBPs with ankyrin repeats and contribute to heavy metal tolerance (such as $\mathrm{Pb}$ and $\mathrm{Cd}$ ), possibly by maintaining or repairing the plasma membrane (PM) when they bind acyl-CoA esters [14-16]. AtACBP3 is an apoplast-targeted class III $\mathrm{ACBP}$ that is involved in leaf senescence and disease resistance [16-18]. Whereas AtACBP1-AtACBP3 are PMor endoplasmic reticulum (ER)-associated ACBPs, the remaining AtACBP4-AtACBP6 are predominantly cytosolic $[7,19]$. The cytosolic AtACBPs have multiple functions and are involved in seed development and oil synthesis through intracellular acyl-CoA trafficking and lipid metabolism [13, 20]. A recent study demonstrated that AtACBP6 is involved in jasmonic acid (JA) biosynthesis in $A$. thaliana phloem because it affects COMATOSE (CTS) function and regulates oxylipin levels [21]. This study implied the possible relationship between lipid metabolism and the JA signaling pathway used during the production of the secondary metabolites produced by several economic crops, including Hevea brasiliensis (H. brasiliensis, the Para rubber tree), which is the most important latex-producing species and is the primary source of high-quality natural rubber worldwide.

The intense metabolic activity of the laticifers is a prerequisite for the reconstitution of lost intracellular components in the exported latex (the laticifer's cytoplasm) of rubber trees after regular bark tapping. The highly specialized laticifer system has no plasmodesmata and is therefore apoplastically isolated from the adjacent cells in the inner bark of rubber trees [22]. This means that laticifers have unique molecular characteristics, which possibly include lipid metabolism mediated by ACBPs like those of other plants. So far, H.brasiliensis ACBPs (HbACBPs) have not yet been identified. In this study, the genome-wide identification of the HbACBPs was performed by mining the recently published $H$. brasiliensis genome sequences [23]. The HbACBPs that were predominantly expressed in the laticifers were then investigated in detail. This study provides valuable information for further investigations into the biological functions of HbACBPs during latex metabolism and stress responses in rubber trees.

\section{Methods}

Plant materials and treatments

Rubber tree clones (Reyan 7-33-97) were planted at the experimental farm of the Chinese Academy of Tropical Agricultural Sciences (CATAS), Hainan, China. Those with similar stem girths were selected for the experiments, and the harvesting system was a half spiral with a tapping frequency of 3 days $(\mathrm{S} / 2 \mathrm{~d} / 3$ system). The plant tissues, latex, male and female flowers, leaves and barks were collected from the rubber trees that had not been previously treated with anything, but were regularly tapped for 2 years, and these trees were also used for stimulation experiments with JA (Sigma-Aldrich, St. Louis, MO, USA) or ethrel/ethephon (ET) (Sigma-Aldrich, St. Louis, MO, USA) according to previously described methods [24]. For the bark tapping (mechanical wound) assays, 7-year-old mature and virgin rubber trees were sequentially tapped seven times using the $S / 2$ $\mathrm{d} / 3$ system. In addition, cultivars of rubber tree (clones Reyan 7-33-97, Reyan 7-20-59, Reyan 8-79, PR107, RRIM600) and Amazon wild germplasms (MT/IT/13 29/8, MT/C/2 10/49, RO/PB/1 2/78, RO/C/9 23/219, $\mathrm{AC} / \mathrm{F} / 7$ 38/63) were used for comparison of the expression difference of $H b A C B P 1$ and $H b A C B P 2$ among different rubber tree clones/germplasms, and they are planted at the National Rubber Tree Germplasm Repository, Hainan, China. Fresh latex was collected from these rubber trees using a $S / 2 d / 3$ system.

\section{Sample collection, dry rubber yield measurement and total RNA preparation}

All the samples were collected in a thermo bottle containing liquid nitrogen and then immediately stored at $-80{ }^{\circ} \mathrm{C}$. Each sample included three independent biological replicates, and each biological replicate comprised the samples collected from six trees (cultivars) or two trees (Amazon wild germplasms). The dry rubber yield of the rubber trees was measured as 
described by Tungngoen et al. [25]. Total RNAs were isolated using the universal plant total RNA extraction kit (BioTeke, Beijing, China) and stored at $-80{ }^{\circ} \mathrm{C}$. The quality and integrity of the total RNAs were evaluated using Nanodrop 2000 (Thermo Scientific, Wilmington, DE, USA) and Bioanalyzer Chip RNA 7500 series II (Agilent, Santa Clara, CA, USA) instruments.

\section{Identification of $\mathrm{HbACBP}$ family genes}

Genes encoding protein $\mathrm{HbACBP}$ sequences that possess one ACB domain were identified using the conserved $A$. thaliana ACB domains as a query to search the CDS sequences from the $H$. brasiliensis genome database [23]. The matched sequences with one $\mathrm{ACB}$ domain were further analyzed for conserved domains using the motif database Pfam (http://pfam.sanger.ac.uk/) or the Pfam27.0 web server (http://pfam.xfam.org/) [26]. The cDNA sequences of the HbACBP (HbACBP1-HbACBP6) genes were confirmed by nucleotide re-sequencing and have been deposited in the NCBI database with accession numbers ranging from KY934263-934268.

\section{Sequence and phylogenetic analysis}

The deduced amino acid sequences of the HbACBP proteins, together with those of the A. thaliana ACBPs, were aligned using the log-expectation (MUSCLE) alignment tool (http://www.ebi.ac.uk/Tools/msa/muscle) with the default program options [27]. The phylogenetic tree was inferred by the Maximum Likelihood method and 100 bootstrap replicates were employed in each analysis to maximize the statistical significance [8]. Then the tree was visualized by MEGA5.05 software [28].

\section{Transcript abundance analysis by RT-qPCR}

The first-strand cDNAs were synthesized using a PrimerScript RT reagent kit with a gDNA eraser (Takara, Dalian, China). The real-time quantitative PCR (RT-qPCR) analysis was carried out using a SYBR Premix Ex Taq ${ }^{\text {Tu}}$ II kit (Takara) on a CFX96 Real-Time System (Bio-Rad, Hercules, CA, USA). The PCR reactions were performed using a $20 \mu \mathrm{L}$ volume sample with the following parameters: $30 \mathrm{~s}$ at $95{ }^{\circ} \mathrm{C}$ for predenaturation, followed by 40 cycles of $95{ }^{\circ} \mathrm{C}$ for $10 \mathrm{~s}$, $58{ }^{\circ} \mathrm{C}$ for $20 \mathrm{~s}$ and $72{ }^{\circ} \mathrm{C}$ for $30 \mathrm{~s}$. The relative expression abundance was determined using the $\triangle \Delta \mathrm{Cq}$ method found in the Bio-Rad CFX Manager 3.0 program (Bio-Rad), or by the $2^{-\triangle \Delta C T}$ method [29], and was calculated from three independent experiments with $H$. brasiliensis $18 S$ rRNA gene as an internal reference. Specific primers for all the selected genes and their efficiencies are listed in the Supporting Information (see Additional file 1). The statistical significance of the different relative transcript abundances was analyzed using SPSS software version 19.0 (Chicago, IL, U.S.A.), and one-way ANOVA with the Student-Newman-Keuls test was used for multiple comparison test to investigate significant differences between groups at the $p<0.05$ and $<0.01$ levels.

\section{Subcellular localization analysis}

The subcellular locations of HbACBP1 and HbACBP2 were determined. The complete HbACBP1 (276 bp) and HbACBP2 (855 bp) coding sequences were respectively fused in-frame with green fluorescent protein (GFP) and ligated into the pBWA(V)HS vector (See Additional files 2 and 3) to generate HbACBP1-GFP and HbACBP2-GFP fusions under the control of the CaMV $35 \mathrm{~S}$ promoter. Their specific primer pairs are listed in Supporting Information (see Additional file 1). The constructs in the destination vectors were confirmed by nucleotide sequencing to verify that the correct fragments were cloned in frame.

Vectors encoding fluorescent protein fusions were individually transfected or co-transfected with pBWA(V)HS-BIP2-mKate, where BIP2 is an ER marker [30], into the mesophyll protoplast cells prepared from the leaves of $A$. thaliana seedlings cultivated at $25^{\circ} \mathrm{C}$ for 10 days using the polyethylene glycol method [31]. The transformed protoplasts were examined under a laser-scanning confocal microscope (Olympus FV1000, Tokyo, Japan).

\section{Results and discussion}

\section{The $H$. brasiliensis ACBP family}

A total of six ACBP family genes were identified in the $H$. brasiliensis genome, and were designated as $H b A C B P 1-H b A C B P 6$, which were similar to those of the model plants $A$. thaliana and rice. After mapping the cDNA sequences of the HbACBP genes to the $H$. brasiliensis genome, the exons and introns for each HbACBP gene were predicted and are shown in Additional file 4 . The domain structures of the ACBPs from A. thaliana, O. sativa ACBPs, and other plant species $[8,11]$ can be used to divide the six $H$. brasiliensis ACBPs into four classes (Fig. 1). Class I H. brasiliensis ACBP contained only one member, HbACBP1 with 92 amino acids, which is similar to A. thaliana ACBP6 (AtACBP6), and class II also had only one member, i.e., HbACBP2 with 285 amino acids that consist of an $\mathrm{ACB}$ domain and ankyrin repeats. HbACBP3 and HbACBP4 were in Class III, which is a large $\mathrm{ACBP}$ class that contains only one $\mathrm{ACB}$ domain like the small HbACBP1 in Class I. HbACBP5 and HbACBP6 belonged to class IV, which possesses an ACB domain and a kelch motif, and they shared a very high identity and had a very similar genomic structure to each other as shown in Additional file 4.

$H$. brasiliensis belongs to the spurge (Euphorbiaceae) family, which includes other economically important 


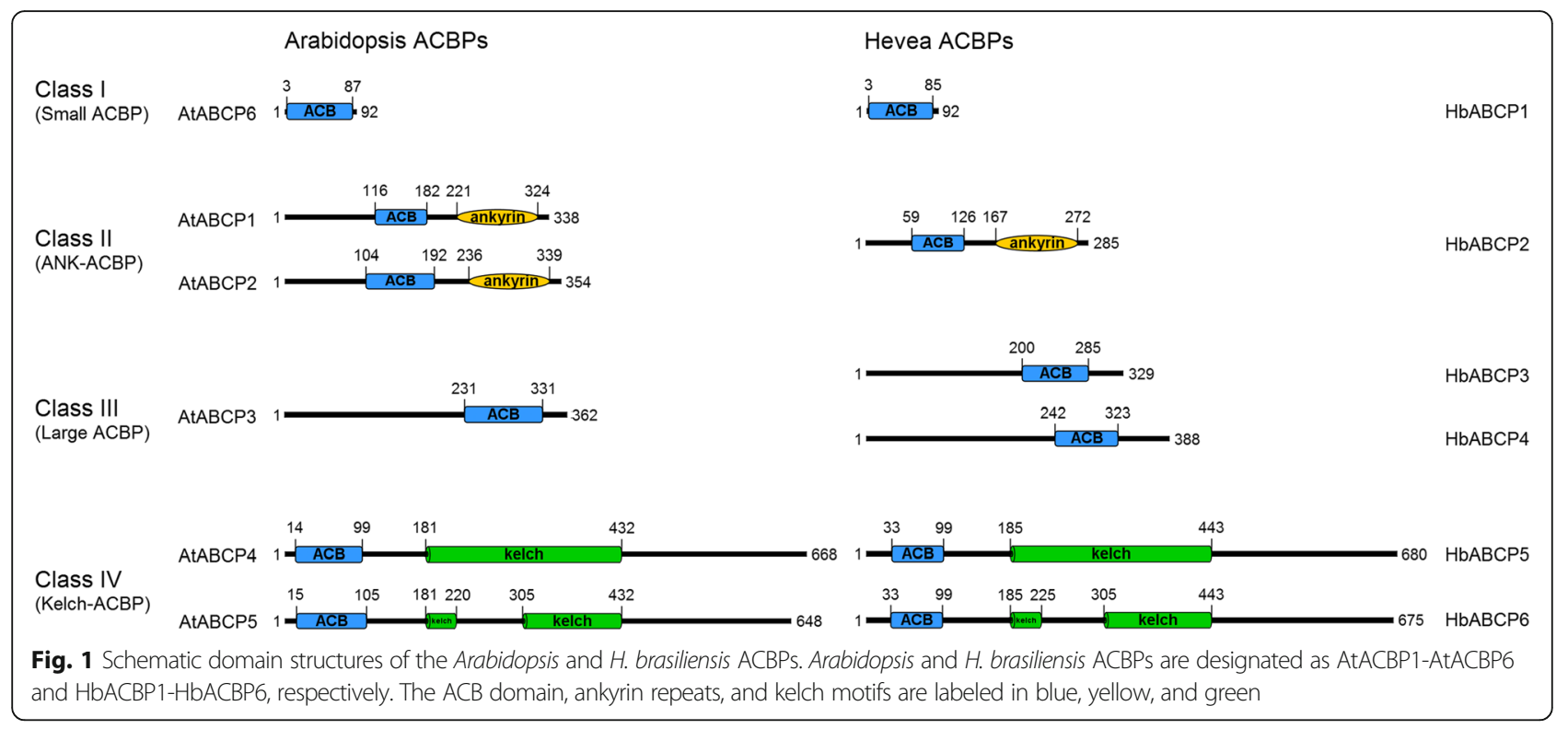

crops, such as cassava (Manihot esculenta), castor bean (Ricinus communis), and physic nut (Jatropha curcas) etc. The genome DNAs of the four crop species have been sequenced [23, 32-34], which allows the gene functions among different species in the spurge family to be compared. After searching the conserved ACB domains, seven, five, and five ACBP members were identified in the $M$. esculenta, $R$. communis, and J. curcas genomes, respectively. A phylogenetic tree analysis demonstrated that every rubber tree ACBP was clustered with those of other closely related species, such as M. esculenta, $R$. communis, and J. curcas, but were further from those of A. thaliana, a distantly related species (Fig. 2). These results further confirm that there is a high conservation and evolutionary relationship between ACBPs in land plants.

\section{Organ/Tissue-specific expression patterns of the HbACBP genes}

The expression patterns of the HbACBP genes were determined in five rubber tree organs or tissues using RT-qPCR. The expressions of six HbACBP transcripts were all detected in mature leaves, bark tissues, female flowers, male flowers, and latex, but the patterns were very different. $H b A C B P 1$ and $H b A C B P 2$ were more predominantly expressed in the latex compared to $H b A C B P 3-H b A C B P 6$, and were more highly expressed in the latex than in other organs or tissues. HbACBP3$H b A C B P 6$ had almost the same expression profiles with relatively high expressions in mature leaf and male flower, moderate expressions in female flower and bark tissue, and markedly low expression in latex (Fig. 3). The results indicate that $H b A C B P 3-H b A C B P 6$ might play more important roles in the development of the $H$. brasiliensis leaf and the male flower but not in the latex production of rubber trees.

Latex is collected through regular bark tapping and is actually the cytoplasm of the laticifer cells in rubber trees [35]. It is the main commercial source of highquality natural rubber worldwide [36]. Anatomical studies have demonstrated that the $H$. brasiliensis laticifer has no plasmodesmata and is apoplastically isolated from adjacent cells in the inner bark [22], which might explain why $H b A C B P 3$ and $H b A C B P 4$ were barely expressed in the laticifers (Fig. 3), since HbACBP3 and HbACBP4 belong to class III ACBPs that are the extracellularly-targeted proteins [17].

\section{Expression profiles of the $H b A C B P s$ in the laticifers of rubber trees}

In rubber trees, the most important agronomic trait is the latex yield, which is highly related to latex metabolism and regeneration in the laticifers. Many studies have investigated the molecular events occurring in the laticifers of rubber trees using transcriptome or proteome techniques [37-40]. Herein, the expression profiles of the six $\mathrm{HbABCP}$ genes in the latex were investigated under bark tapping (a mechanical wound), exogenous ET (a releaser of ethylene), and JA stimulation. A RTqPCR analysis showed that the HbACBP genes had diverse expression patterns in response to the treatments, which is consistent with the inducible expression of the ACBP genes. Bark tapping can significantly increase the transcript levels of $H b A C B P 1$ and $H b A C B P 2$, but greatly suppress the expression of $H b A C B P 3-H b A C B P 6$ (Fig. 4). In comparison with bark tapping, ET can greatly enhance the expression level of $H b A C B P 1$ (Fig. 5), and slightly increase $H b A C B P 5$ expression although this 


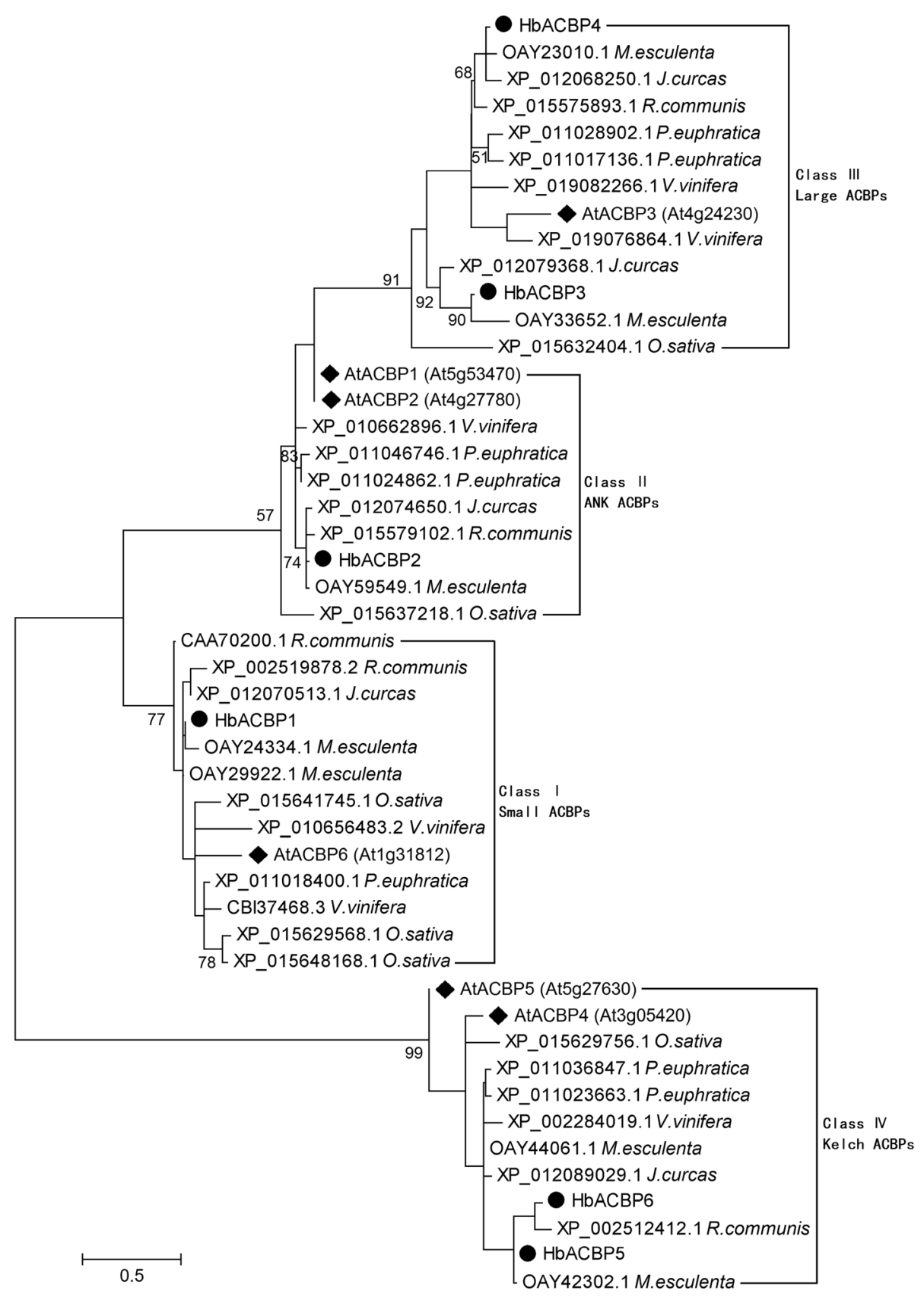

Fig. 2 Phylogenetic tree of the ACBPs from H. brasiliensis and other plant species. The amino acid sequences of all the selected proteins were aligned using the MUSCLE program and subjected to phylogenetic analysis by the Distance with Maximum Likelihood method using MEGA5.05 software. The numbers on the nodes indicate the bootstrap values (> 50\%) after 100 replicates. The scale bar indicates the estimated number of amino acid substitutions per site. $\bullet$ indicates the six rubber tree ACBPs; indicates Arabidopsis ACBPs

result was not significant (fold change $\leq 1.5$ ), but had almost no effects on the expression of $H b A C B P 2$ and $H b A C B P 6$, and greatly suppressed the expression of $H b A C B P 3$ and $H b A C B P 4$ (Fig. 5). JA can significantly induce the expression of $H b A C B P 1$ and $H b A C B P 2$, but had no influence on other HbACBP genes (Fig. 5). These data indicated $H b A C B P 1$ and $H b A C B P 2$ are the two major ACBP genes that are predominantly expressed in the laticifers and can be induced by bark tapping and treatments with ET and JA. In addition, the different expression patterns of $H b A C B P 1$ and $H b A B C P 2$ between 5 rubber tree cultivars and 5 Amazon wild germplasms indicate that $H b A C B P 1$ and $H b A B C P 2$ had higher expression levels in the laticifers of the rubber tree cultivars with higher latex production than the Amazon wild germplasms with relatively lower latex yield (Fig. 6). 


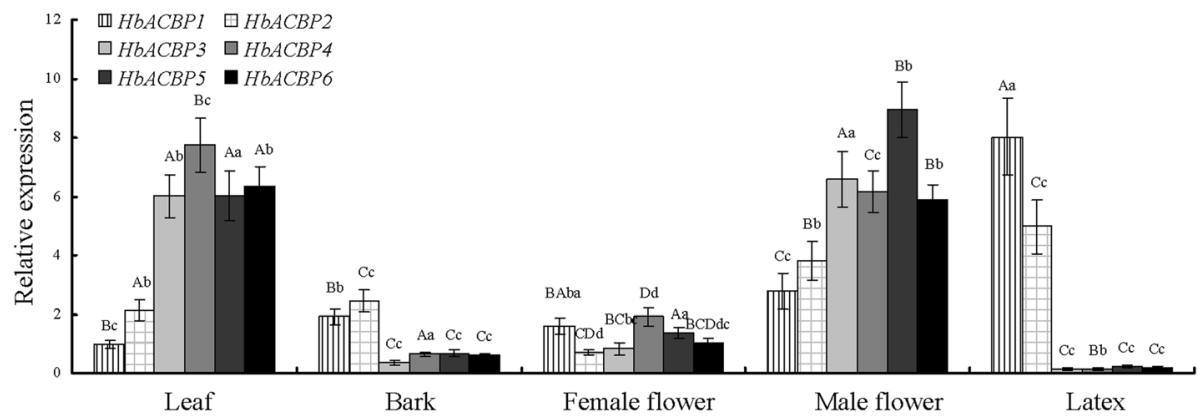

Fig. 3 Expression patterns of the HbACBP genes in five different rubber tree organs or tissues. Three independent samples were used for RT-qPCR analysis, and the transcript levels of each gene were determined. The values are shown as the mean $\pm \mathrm{S}$. D of three independent biological replicates. Different uppercase and lowercase letters above the bars indicate differences between mean values within each gene at the 0.01 and 0.05 significance levels, respectively

The characteristic gene expression of $H b A C B P s$ in the latex revealed that $H b A C B P 1$ and $H b A C B P 2$ play pivotal roles during lipid metabolism and responses to bark tapping or ET, JA stimulation, and that they are significantly related to latex metabolism and production in rubber trees. ET (applied as chloro-2-ethylphosphonic acid) is commonly used to stimulate latex production [41]. JA is a key inducer of laticifer differentiation [42], and might be a regulator of rubber biosynthesis-related genes [43] because it acts as an elicitor during the induction of plant secondary metabolites [44]. Bark tapping might trigger the latex metabolic switch to turn on, and can activate latex regeneration and rubber biosynthesis, which enhances latex yield [45]. Therefore, further investigation is needed to elucidate HbACBP1- and HbACBP2-mediated lipid metabolism and phospholipidic

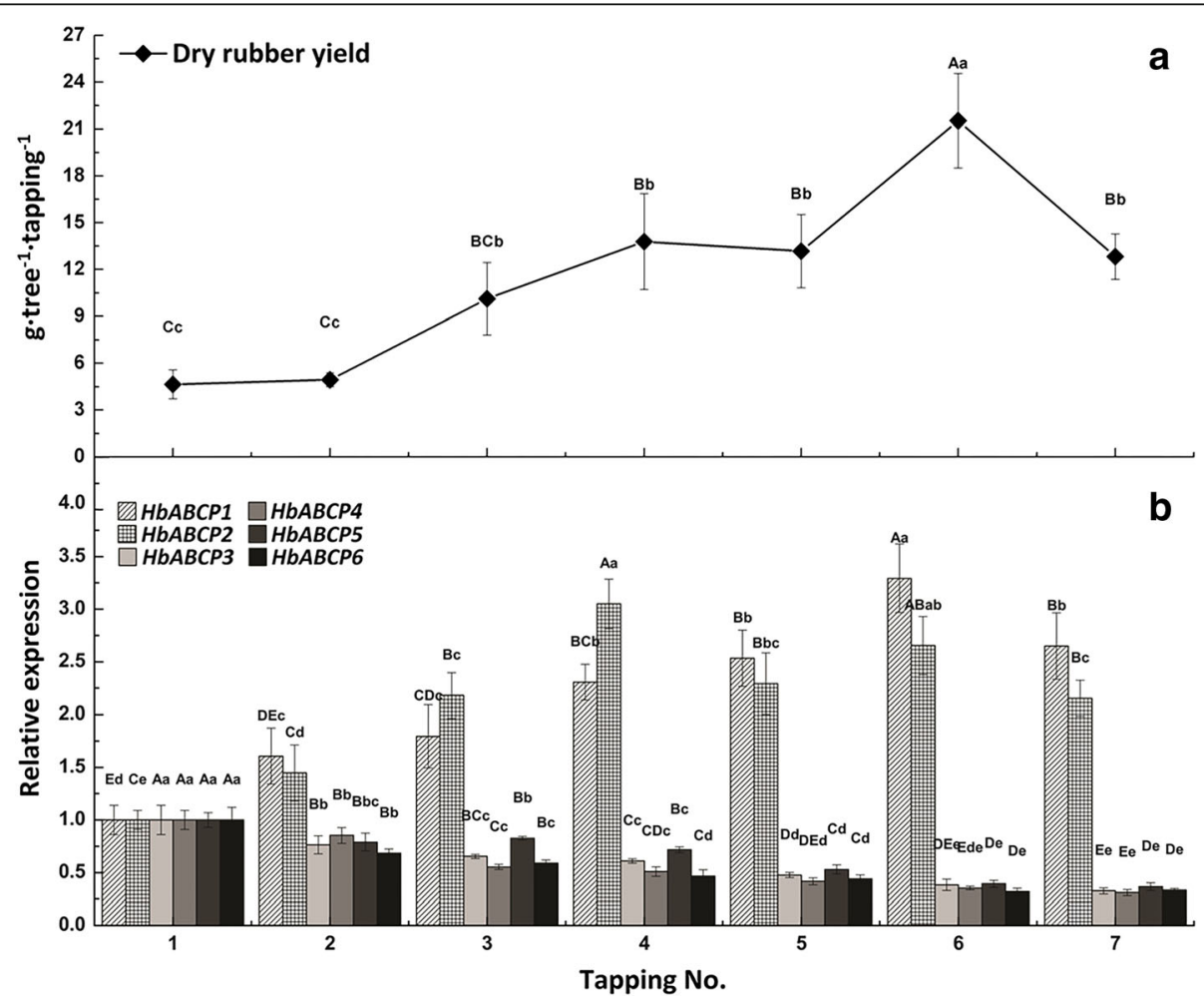

Fig. 4 Effect of consecutive bark tappings on dry rubber yield and the HbACBP genes expression. a Effect of consecutive bark tapping on dry rubber yield, $\mathbf{b}$ Effects of bark tapping on the expression of HbACBP1 and HbACBP2 genes in the latex of rubber trees. Fresh latex was collected from mature and virgin rubber trees from every bark tapping. The transcript abundance of each gene was detected by RT-qPCR. The standard bars were obtained from at least three independent replications and the results were given as mean \pm S.D. Different uppercase and lowercase letters above the bars indicate differences between mean values within each gene at the 0.01 and 0.05 significance levels, respectively 


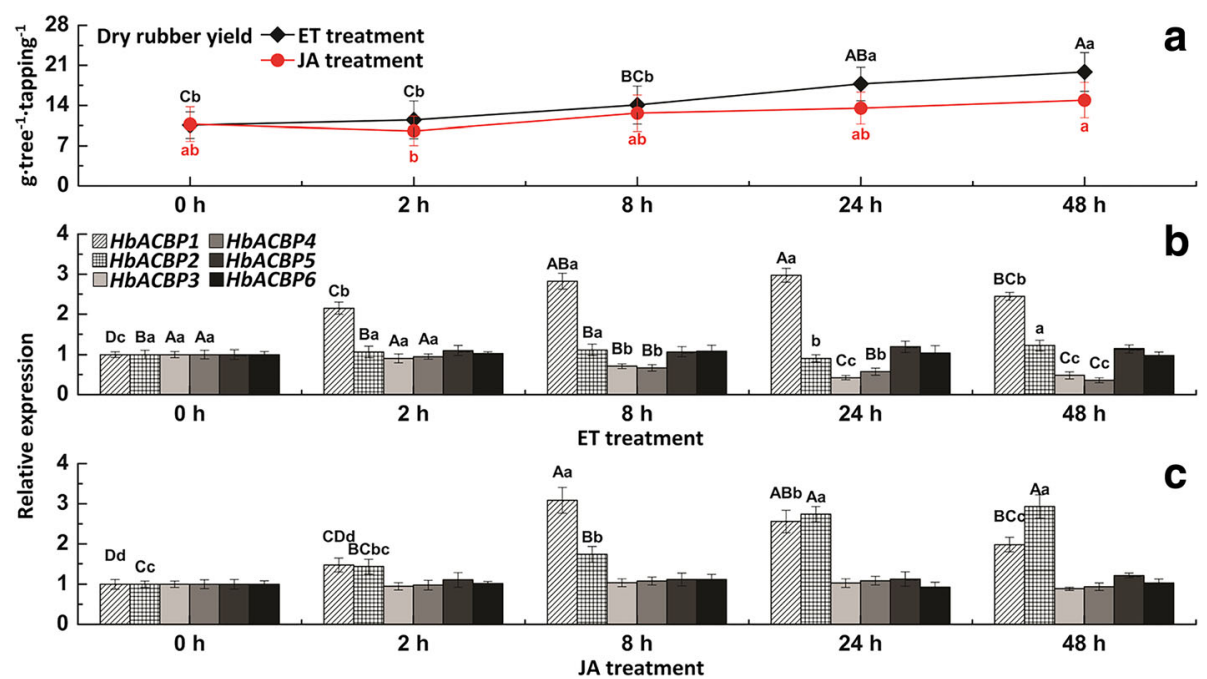

Fig. 5 Comparison of ET and JA stimulation on dry rubber yield and HbACBP genes expression. a Changes in dry rubber yield, $\mathbf{b}$ Expression patterns of HbACBP genes in the latex of rubber trees subjected to ET treatment, $\mathbf{c}$ Expression patterns of HbACBP genes in the latex of rubber trees subjected to JA treatment. Fresh latex was collected from exogenous ET- or JA-treated rubber trees that were regularly tapped for 2 years. The transcript abundance of each gene was detected by RT-qPCR. The standard bars were obtained from at least three independent replications and the results were given as mean \pm S.D. Different uppercase and lowercase letters above the bars indicate differences between mean values within each gene at the 0.01 and 0.05 significance levels, respectively

signaling, and their relationships with latex metabolism in the H. brasiliensis laticifers.

\section{Subcellular localization and possible functions of HbACBP1 and HbACBP2}

The biological function of a protein is closely related to its subcellular localization. To investigate the possible involvement of HbACBPs in latex metabolism, the predominantly laticifer-expressed HbACBP1 and HbACBP2 were further selected for subcellular localization analysis. HbACBP1 and HbACBP2 were fused with the GFP, and were transiently expressed in A. thaliana leaf protoplasts. ACBP6 (AtACBP6), a class I ACBP, is localized in the cytosol [7], which is the same as A. thaliana.
HbACBP1 is also a cytosol protein (Fig. 7 a-d). HbACBP2-GFP was co-transfected into $A$. thaliana leaf protoplasts with mKate-tagged ER marker BIP2, and the results showed that HbACBP2 is an ER-associated protein but is not in the PM (Fig. 7 e-i), which agrees with results that show that AtACBP1/2 is predominantly located in the ER [7].

A recent study reported that AtACBP6 is involved in JA-biosynthesis of the sieve elements in $A$. thaliana phloem tissues [21]. Therefore, an intriguing suggestion is that HbACBP1 is potentially involved in JA formation in the laticifer cells of rubber trees, since JA acts as a key regulator during laticifer differentiation and rubber biosynthesis [42, 43]. In rubber tree phloem, both

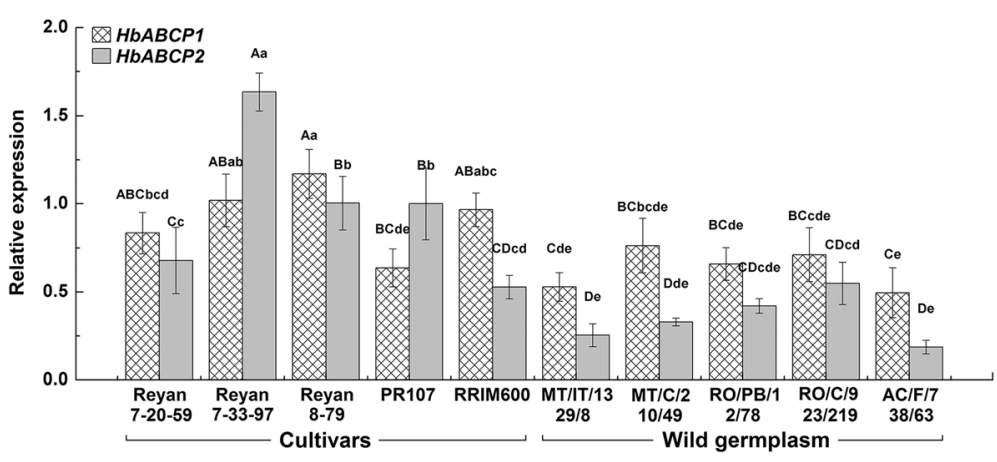

Fig. 6 Differential expressions of the HbACBP1 and 2 genes in different rubber tree clones or germplasms. Fresh latex was collected from 5 Amazon wild germplasms and 5 cultivars rubber tree clones. The transcript abundance of each gene was detected by RT-qPCR. The standard bars were obtained from at least three independent replications and the results were given as mean \pm S.D. Different uppercase and lowercase letters above the bars indicate differences between mean values within each gene at the 0.01 and 0.05 significance levels, respectively 


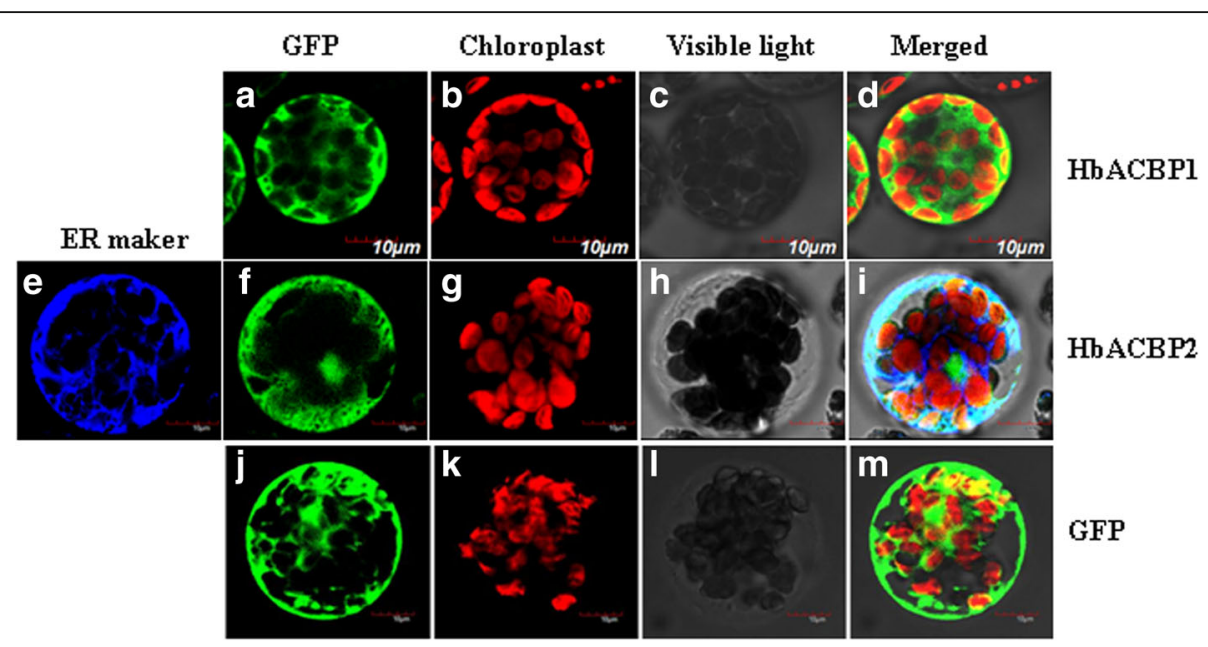

Fig. 7 Subcellular localization of HbACBP1 and HbACBP2 in Arabidopsis leaf protoplasts. a-d HbACBP1-GFP fusion protein; e-i co-transfection of HbACBP2-GFP fusion protein and the ER marker; $\mathbf{j}-\mathbf{m}$ GFP control; $\mathbf{a}, \mathbf{f}$, and $\mathbf{j}$ transient expression of GFP; $\mathbf{b}$, $\mathbf{g}$, and $\mathbf{k}$ chloroplast autofluorescence; $\mathbf{c}, \mathbf{h}$, and I visible light; $\mathbf{d}, \mathbf{i}$, and $\mathbf{m}$, merged images; and $\mathbf{e} E R$ marker. Scale bar $=10 \mu \mathrm{m}$

laticifer cells and sieve elements originate from the vascular cambia, but they belong to two different kinds of cell types and do not have any linkages (including plasmodesmata) between them [46]. As far as the abovementioned studies are concerned, a JA-biosynthesis pathway, which is independent from that in the sieve elements and other cells, might exist in the laticifer cells, and this hypothesis was supported by the identification of all the genes related to JA-biosynthesis pathway in the isolated latex of the laticifers.

In A. thaliana, AtACBP6 may regulate JA composition by affecting the function of CTS [21]. CTS is an ATP-binding cassette (ABC) transporter (At4g39850, AtABCD1) belonging to subfamily $A B C D$, and is used to transport JA precursors into peroxisomes [47]. The rubber tree latex transcriptome analysis identified two $\mathrm{ABCD}$ genes, $H b A B C D 1$ and $H b A B C D 2$ [24]. Both HbACBD1 and AtABCD1 comprise 1337 amino acids with a (TMD-NBD) $)_{2}$ domain structure. They have an identity of $78 \%$ for their amino acid sequences, which implies that HbACBD1 may have the same role as the $A$. thaliana CTS (AtABCD1), and the functional relationship between HbACBP1 and HbACBD1 needs to be further revealed during JA-biosynthesis in rubber tree laticifers. Rubber trees often suffer from regular bark tapping for latex collection. Bark tapping is a mechanical wound and could act as a stress elicitor [48], which can greatly increase the metabolic activity of the laticifers [45]. Since lipid signaling functions importantly in plant responses to various abiotic stresses [49]; therefore, the integration of lipid signaling and wound signaling into phytohormone-regulated pathways could be used to elucidate the mechanisms underlying the latex metabolism of rubber trees.

\section{Conclusions}

Six members of the $H$. brasiliensis ACBP family were identified and structurally compared to $A$. thaliana ACBPs. The HbACBP genes are organ/tissue-specifically expressed and have different expression patterns in response to stimulation by ET, JA, and bark tapping (mechanical wound). $H b A C B P 1$ and $H b A C B P 2$ are more prominently expressed in the $H$. brasiliensis laticifers. Their expressions can be markedly increased by bark tapping or ET, JA stimulation, and have significant correlation with latex production, which suggest that HbACBP1 and HbACBP2 play crucial roles in the lipid and latex metabolism in rubber tree laticifers. Further investigations are needed to elucidate the relationship between the ACBP-mediated lipid metabolism and latex production of rubber trees.

\section{Additional files}

Additional file 1: Primers and their sequences used in this study. (DOC $44 \mathrm{~kb}$ )

Additional file 2: The vector of HbACBP1 for subcellular localization. (TIFF $911 \mathrm{~kb}$ )

Additional file 3: The vector of HbACBP2 for subcellular localization. (TIFF $914 \mathrm{~kb}$ )

Additional file 4: Linear presentation of the exon-intron structures for the Hevea ACBP family genes. (TIFF $430 \mathrm{~kb}$ )

\section{Abbreviations}

A. thaliana: Arabidopsis thaliana; ACBD: acyl-CoA-binding domain; ACBP: AcylCOA-binding protein; CTS: COMATOSE; ER: Endoplasmic reticulum; ET: Ethephon; GFP: Green fluorescent protein; H. brasiliensis: Hevea brasiliensis; JA: Jasmonic acid; PM: Plasma membrane; RT-qPCR: Real-time quantitative PCR 


\section{Acknowledgements}

We are very grateful to the National Infrastructure for Crop Germplasm ResourcesNational Infrastructure for Rubber Tree Germplasm Resources for providing the cultivars and Amazon wild germplasms rubber trees in the research.

\section{Funding}

This research was supported by the Major Scientific \& Technological Projects of Hainan Province (grant No. ZDKJ2016020), the Central Public-interest Scientific Institution Basal Research Fund for Chinese Academy of Tropical Agricultural Sciences (grant No. 1630022015001), and the National Natural Science Foundation of China (NSFC) (grant No. 31770642)

\section{Availability of data and materials}

All data are fully available without restriction.

\section{Authors' contributions}

RZZ conceived and designed the experiments. ZYN, YHW, YL, GJK, and HDQ performed the experiments. RZZ, CTW and ZYN analyzed the data. RZZ and ZYN wrote the manuscript. All authors read and approved the final manuscript.

\section{Ethics approval and consent to participate}

Not applicable

\section{Consent for publication}

Not applicable

\section{Competing interests}

The authors declare that they have no competing interests.

\section{Publisher's Note}

Springer Nature remains neutral with regard to jurisdictional claims in published maps and institutional affiliations.

\section{Author details}

'Rubber Research Institute \& Key Laboratory of Biology and Genetic Resources of Rubber Trees, Ministry of Agriculture of China, Chinese Academy of Tropical Agricultural Sciences, Danzhou, Hainan 571737, China.

${ }^{2}$ College of Agriculture, Hainan University, Haikou 570228, China.

Received: 6 August 2017 Accepted: 22 December 2017

Published online: 02 January 2018

\section{References}

1. Chye ML. Arabidopsis CDNA encoding a membrane-associated protein with an acyl-CoA binding domain. Plant Mol Biol. 1998;38:827-38. doi: https://doi. org/10.1023/A:1006052108468.

2. Rosendal J, Ertbjerg P, Knudsen J. Characterization of ligand binding to acylCoA-binding protein. Biochem J. 1993;290:321-6. https://doi.org/10.1042/ bj2900321.

3. Leung KC, Li HY, Mishra G, Chye ML. ACBP4 and ACBP5, novel Arabidopsis acyl-CoA-binding proteins with kelch motifs that bind oleoyl-CoA. Plant Mol Biol. 2004;55:297-309. https://doi.org/10.1007/s11103-005-0642-7.

4. Knudsen J, Faergeman NJ, Skøtt H, Hummel R, Børsting C, Rose TM, et al. Yeast acyl-CoA-binding protein: acyl-CoA-binding affinity and effect on intracellular acyl-CoA pool size. Biochem J. 1994;302:479-85. https://doi.org/ 10.1042/bj3020479.

5. Faergeman NJ, Knudsen J. Role of long-chain fatty acyl-CoA esters in the regulation of metabolism and cell signaling. Biochem J. 1997;323:1-12. https://doi.org/10.1042/bj3230001

6. Burton M, Rose TM, Faergeman NJ, Knudsen J. Evolution of the acyl-CoA binding protein (ACBP). Biochem J. 2005;392:299-307. https://doi.org/10. 1042/BJ20050664.

7. Xiao S, Chye ML. An Arabidopsis family of six acyl-CoA-binding proteins has three cytosolic members. Plant Physiol Biochem. 2009;47:479-84. https://doi. org/10.1016/j.plaphy.2008.12.002.

8. Meng W, Su YCF, Saunders RMK, Chye ML. The rice acyl-CoA binding protein gene family: phylogeny, expression and functional analysis. New Phytol. 2011:189:1170-84. https://doi.org/10.1111/j.1469-8137.2010.03546.x

9. Raboanatahiry NH, Yin YT, Chen L, Li MT. Genome-wide identification and phylogenic analysis of kelch motif containing ACBP in Brassica napus. BMC Genomics. 2015;16:512. https://doi.org/10.1186/s12864-015-1735-6.
10. Pastor S, Sethumadhavan K, Ullah AH, Gidda S, Cao H, Mason C, et al. Molecular properties of the class III subfamily of acyl-coenyzme A binding proteins from tung tree (Vernicia fordii). Plant Sci. 2013;204:79-88. https:// doi.org/10.1016/j.plantsci.2012.12.009.

11. Du ZY, Arias T, Meng W, Chye ML. Plant acyl-CoA-binding proteins: an emerging family involved in plant development and stress responses. Prog Lipid Res. 2016;63:165-81. https://doi.org/10.1016/j.plipres.2016.06.002.

12. Xiao S, Chye ML. New roles for acyl-CoA-binding proteins (ACBPs) in plant development, stress responses and lipid metabolism. Prog Lipid Res. 2011; 50:141-51. https://doi.org/10.1016/j.plipres.2010.11.002.

13. Ye ZW, Chye ML. Plant cytosolic acyl-CoA-binding proteins. Lipids. 2016;51: 1-13. https://doi.org/10.1007/s11745-015-4103-z.

14. Xiao S, Gao W, Chen QF, Ramslingam S, Chye ML. Overexpression of membrane-associated acyl-CoA-binding protein ACBP1 enhance lead tolerance in Arabidopsis. Plant J. 2008:54:141-51. https://doi.org/10.1111/j. 1365-313X.2008.03402.X.

15. Gao W, Xiao S, Li HY, Tsao SW, Chye ML. Arabidopsis thaliana acyl-CoAbinding protein ACBP2 interacts with a heavy-metal-binding farnesylated protein ATF6. New Phytol. 2009;181:89-102. https://doi.org/10.1111/j.14698137.2008.02631.X

16. Leung KC, Li HY, Xiao S, Tse MH, Chye ML. Arabidopsis ACBP3 is an extracellularly targeted acyl-CoA-binding protein. Planta. 2006;223:871-81. https://doi.org/10.1007/s00425-005-0139-2.

17. Xiao S, Gao W, Chen QF, Chan SW, Zheng SX, Ma J, et al. Overexpression of Arabidopsis acyl-CoA-binding protein ACBP3 promotes starvation-induced and age-dependent leaf senescence. Plant Cell. 2010;22:1463-82. https://doi. org/10.1105/tpc.110.075333.

18. Xiao S, Chye ML. Overexpression of Arabidopsis ACBP3 enhances NPR1dependent plant resistance to Pseudomonas syringe pv. tomoto DC3000. Plant Physiol. 2011;156:2069-81. https://doi.org/10.1104/pp.111.176933.

19. Xiao S, Li YH, Zhang JP, Chan SW, Chye ML. Arabidopsis acyl-CoA-binding proteins ACBP4 and ACBP5 are subcellularly localized in the cytosol and ACBP4 depletion affects membrane lipid composition. Plant Mol Biol. 2008; 68:571-83. https://doi.org/10.1007/s11103-008-9392-7.

20. Hsiao AS, Haslam RP, Michaelson LV, Liao P, Chen QF, Sooriyaarachchi S, et al. Arabidopsis cytosolic acyl-CoA-binding proteins ACBP4, ACBP5 and ACBP6 have overlapping but distinct roles in seed development. Biosci Rep. 2014;34:865-77. https://doi.org/10.1042/BSR20140139.

21. Ye ZW, Lung SC, Hu TH, Chen QF, Suen YL, Wang M, et al. Arabidopsis acyl-CoAbinding protein ACBP6 localizes in the phloem and affects jasmonate composition. Plant Mol Biol. 2016;92:717-30. https://doi.org/10.1007/s11103-016-0541-0.

22. de Fay $E_{1}$ Jacob JL. Anatomical organization of the laticiferous system in the bark. In: d'Auzac J, Jacob JL, Chrestin H, editors. Physiology of rubber tree latex. Boca Raton: CRC Press; 1989. p. 3-14.

23. Tang C, Yang M, Fang Y, Luo Y, Gao S, Xiao X, et al. The rubber tree genome reveals new insights into rubber production and species adaptation. Nat Plants. 2016;2:16073. https://doi.org/10.1038/nplants.2016.73.

24. Nie Z, Kang G, Li Y, Dai L, Zeng R. Whole-transcriptome survey of the putative ATP-binding cassette $(A B C)$ transporter family genes in the latexproducing laticifers of Hevea brasiliensis. PLoS One. 2015;10:e0116857. https://doi.org/10.1371/journal.pone.0116857.

25. Tungngoen K, Kongsawadworakul P, Viboonjun U, Katsuhara M, Brunel N, Sakr S, et al. Involvement of HbPIP2;1 and HbTIP1;1 Aquaporins in ethylene stimulation of latex yield through regulation of water exchanges between inner liber and latex cells in Hevea brasiliensis. Plant Physiol. 2009;151: 843-56. https://doi.org/10.1104/pp.109.140228.

26. Punta M, Coggill PC, Eberhardt RY, Mistry J, Tate J, Boursnell C, et al. The Pfam protein families database. Nucleic Acids Res. 2012;40:D290-301. https://doi.org/10.1093/nar/gkr1065.

27. Edger RC. MUSCLE: multiple sequence alignment with high accuracy and high throughput. Nucleic Acids Res. 2004;32:1792-7. https:/doi.org/10.1093/nar/gkh340.

28. Tamura K, Peterson D, Peterson N, Stecher G, Nei M, Kumar S. MEGA5: molecular evolutionary genetics analysis using maximum likelihood, evolutionary distance, and maximum parsimony methods. Mol Biol Evol. 2011;28:2731-9. https://doi.org/10.1093/molbev/msr121.

29. Livak KJ, Schmittgen TD. Analysis of relative gene expression data using real-time quantitative PCR and the 2- $\Delta \Delta C T$ method. Methods. 2001;25: 402-8. https://doi.org/10.1006/meth.2001.1262.

30. Mravec J, Skůpa P, Bailly A, Hoyerová K, Křeček P, Bielach A, et al. Subcellular homeostasis of phytohormone auxin is mediated by the ER-localized PIN5 transporter. Nature. 2009;459:1136-40. https://doi.org/10.1038/nature08066. 
31. Zhang W, Wu R. Efficient regeneration of transgenic plants from rice protoplasts and correctly regulated expression of the foreign gene in the plants. Theor Appl Genet. 1988;76:835-40. https://doi.org/10.1007/BF00273668.

32. Wu P, Zhou C, Cheng S, Wu Z, Lu W, Han J, et al. Integrated genome sequence and linkage map of physic nut (Jatropha curcas L.), a biodiesel plant. Plant J. 2015;81:810-21. https://doi.org/10.1111/tpj.12761.

33. Wang W, Feng B, Xiao J, Xia Z, Zhou X, Li P, et al. Cassava genome from a wild ancestor to cultivated varieties. Nat Commun. 2014;5:5110. https://doi. org/10.1038/ncomms6110.

34. Chan AP, Crabtree J, Zhao Q, Lorenzi H, Orvis J, Puiu D, et al. Draft genome sequence of the ricin-producing oilseed castor bean. Nat Biotechnol. 2010; 28:951-6. https://doi.org/10.1038/nbt.1674

35. d'Auzac J, Jacob JL. The composition of latex from Hevea brasiliensis as a laticiferous cytoplasm. In: d'Auzac J, Jacob JL, Chrestin H, editors. Physiology of rubber tree latex. Boca Raton: CRC Press; 1989. p. 89-94.

36. van Beilen JB, Poirier Y. Establishment of new crops for the production of natural rubber. Trends Biotechnol. 2007;25:522-9. https://doi.org/10.1016/j. tibtech.2007.08.009.

37. Chow KS, Mat-Isa MN, Bahari A, Ghazali AK, Alias H, Zainuddin ZM, et al. Metabolic routes affecting rubber biosynthesis in Hevea brasiliensis latex. J Exp Bot. 2012;63:1863-71. https://doi.org/10.1093/jxb/err363.

38. Dai L, Kang G, Li Y, Nie Z, Duan C, Zeng R. In-depth proteome analysis of the rubber particles of Hevea brasiliensis (para rubber tree). Plant Mol Biol. 2013;82:155-68. https://doi.org/10.1007/s11103-013-0047-y.

39. Dai L, Kang G, Nie Z, Li Y, Zeng R. Comparative proteomic analysis of latex from Hevea brasiliensis treated with Ethrel and methyl jasmonate using iTRAQ-coupled two-dimensional LC-MS/MS. J Proteome. 2016;132:167-75. https://doi.org/10.1016/j.jprot.2015.11.012.

40. Li D, Zeng R, Li Y, Zhao M, Chao J, Li Y, et al. Gene expression analysis and SNP/InDel discovery to investigate yield heterosis of two rubber tree F1 hybrids. Sci Rep. 2016;6:24984. https://doi.org/10.1038/srep24984.

41. Abraham PD, Wycherley PR, Pakianathan SW. Stimulation of latex flow in Hevea brasiliensis of 4-amino-3, 5, 6-trichloropicolinic acid and 2chloroethane-phosphonic acid. Rubber Chem Technol. 1972;45:883-99. https://doi.org/10.5254/1.3542895

42. Hao BZ, Wu JL. Laticifer differentiation in Hevea brasiliensis: induced by exogenous jasmonic acid and linolenic acid. Ann Bot. 2000;85:37-43. https://doi.org/10.1006/anbo.1999.0995.

43. Zeng R, Duan C, Li X, Tian W, Nie Z. Vacuolar-type inorganic pyrophosphatase located on the rubber particle in the latex is an essential enzyme in regulation of the rubber biosynthesis in Hevea brasiliensis. Plant Sci. 2009:176:602-7. https://doi.org/10.1016/j.plantsci.2009.01.009.

44. De Geyter N, Gholami A, Goormachtig S, Goossens A. Transcritptional machineries in jasmonate-elicited plant secondary metabolism. Trends Plant Sci. 2012;17:349-59. https://doi.org/10.1016/j.tplants.2012.03.001.

45. Annamalainathan K, Krishnakumar R, Jacob JL. Tapping induced changes in respiratory metabolism, ATP production and reactive oxygen species scavenging in Hevea. J Rubber Res. 2001:4:245-54.

46. Wu JL, Hao BZ. Ultrastructure of P-protein in Hevea brasiliensis during sieve-tube development and after wounding. Protoplasma. 1990;153:186-92. https://doi.org/ 10.1007/BF01354003.

47. Theodoulou FL, Job K, Slocombe SP, Footitt S, Holdsworth M, Baker A, et al. Jasmonic acid levels are reduced in COMATOSE ATP-binding cassette transporter mutants. Implications for transport of jasmonate precursors into peroxisomes. Plant Physiol. 2005;137:835-40. https://doi.org/10.1104/pp.105.059352.

48. Leon J, Rojo E, Sanchez-Serrano JJ. Wound signalling in plants. J Exp Bot. 2001;354:1-9. https://doi.org/10.1093/jexbot/52.354.1.

49. Hou QC, Ufer G, Bartels D. Lipid signalling in plant responses to abiotic stress. Plant Cell Environ. 2016:39:1029-48. https://doi.org/10.1111/pce.12666.

\section{Submit your next manuscript to BioMed Central and we will help you at every step:}

- We accept pre-submission inquiries

- Our selector tool helps you to find the most relevant journal

- We provide round the clock customer support

- Convenient online submission

- Thorough peer review

- Inclusion in PubMed and all major indexing services

- Maximum visibility for your research

Submit your manuscript at www.biomedcentral.com/submit
C) Biomed Central 